\title{
Characteristics of the Pedagogical Innovator in a University Strongly Committed to Research and Across Disciplines
}

\author{
Anne M. Walder ${ }^{1}$ \\ ${ }^{1}$ School of Education, University of Montreal, Montreal, Quebec, Canada \\ Correspondence: Anne M. Walder, Université de Montréal, Faculté des sciences de l'éducation, Département de \\ psychopédagogie et d'andragogie, Case postale 6128, succursale Centre-Ville, Montréal, QC H3C 3J7. E-mail: \\ anne.mai.walder@umontreal.ca
}

Received: May 20, 2014

doi:10.5539/jedp.v5n1p119

\author{
Accepted: January 27, 2015 \\ Online Published: April 24, 2015 \\ URL: http://dx.doi.org/10.5539/jedp.v5n1p119
}

\begin{abstract}
While innovation is a central concern in higher education, I have sought to understand those professors who innovate. This qualitative research focuses in particular on pedagogical innovators in the context of a university strongly committed to research, the Université de Montréal, and explores the impact of disciplinary culture on pedagogical innovators' profiles. This research reveals the characteristics of the innovators interviewed and underlines the impact of the pure science and applied science axis on pedagogical innovator characteristic diversity.
\end{abstract}

Keywords: pedagogical innovators, characteristics of innovators, disciplinary culture, higher education

\section{Introduction}

According to the traditions of academic culture, university teaching remains one of the few professions for which one does not need training in order to practice. The only requirement is a doctorate attesting to one's credentials in the research subject taught with, in general, no minimum requirements in terms of teaching credentials, or pedagogical, communication, assessment or supervision skills. In this context, it is unlikely that professors will find the time to reflect upon their understanding of the act of teaching or to glance at pedagogical innovations and potential alternatives that might improve their teaching, unless they are compelled by curiosity to enrol on a course specifically dedicated to the teaching practice of higher education. Professors are rewarded for having faithfully conformed to the values and visions of university protagonists, so it is of no benefit for them to stray from the traditionalist path. An excellent researcher, can only be a good teacher and it is the students who are not able to properly assess the quality of his teaching. Hence, these beliefs are those that continue to shape the academic environment (Fox, 1983; Loiola \& Tardif, 2001).

That said, a change in the way the profession of professor-researcher is regarded can be noticed. First, the recruitment of professors has been decentralised to units, which draft the job advertisements and increasingly include teaching-related requirements in these. Thus, university professors are invited to attend pedagogical training courses. Today, we know that university teaching is a learnt occupation (Donnay \& Romainville, 1996). Teaching skills are built and developed, among others, through practice and revolve around the "practical skills" or "action skills" used by professors in class to deal with the urgency and uncertainty of real situations (Piot, 2008). I underline the fact that it is in action and vis-à-vis students that professors construct their skills.

While, method diversity and pedagogical advice from groups of practitioners and mentoring are recommended (Knight, 2002), promoting and supporting pioneering pedagogical projects have been a top priority for certain committed universities. For example, few Anglo-Saxon and Canadian universities are making pedagogical initiative funds available aimed at financing the implementation of pedagogical innovations (Weimer \& Lenz, 1991).

Pedagogical teaching support centres were first developed in English-language universities (ibid.), but are widespread today among university establishments. The programmes offer four specific types of support dependent on the establishment. These are: training in university pedagogy, individual advice, teaching assessment and applied pedagogical research. The pedagogical innovation support funds aim to improve the 
quality of university training, and to valorise the "teaching" aspect of university work by supporting professors who wish to innovate in their teaching practice and develop their skills in the field whilst contributing to the best learning conditions for students and kindling reflection on teaching and learning within the university.

Thus, teaching practice support programmes form part of the university landscape and advocate the valorisation of teaching, pedagogical support for professors and act as a springboard for pedagogical innovation.

\section{The Aim and Research Question}

The aim of the research focuses on a better understanding of the pedagogical innovator in the context of a university strongly committed to research. In the absence of studies on pedagogical innovators at the Université de Montréal, this study contributes new knowledge to this field. Thus, I will explore the following research questions:

1) What are the characteristics of the innovators in a university strongly committed to research?

2) What are the innovators' characteristics in a university strongly committed to research according to disciplinary culture?

\section{What do We Know about Pedagogical Innovators?}

At this junction, I find it appropriate to explore the professor fittingly called the pedagogical innovator. Pedagogical innovations are either initiated top-down by the institution or bottom-up by the spontaneous and often isolated actions of university teachers. Pedagogical innovators are those professors who implement one or more pedagogical innovations in their teaching. In their study, Hannan, English and Silver (1999) highlight that pedagogical innovators draw inspiration from their professional and lecturing experience, but also that pedagogical innovations influence their research work.

I note the complex nature of identifying pedagogical innovators among teachers. In a study he conducted on the matter, Béchard (2000) reports that in the past it was difficult to locate and identify pedagogical innovators. His work facilitated a classification into three types: self-proclaimed innovators, peer-recognised innovators and model professors.

I can distinguish seven categories of pedagogical innovators. In her study, Falchikov (1993) looked at the attitudes and values of sixty teachers, pedagogical innovators, in a Scottish polytechnic institution. In effect, Falchikov classified them into seven categories of actor: student-focused innovators, traditionalist innovators, staff-focused innovators, staff-under-pressure innovators, senior innovators, professional innovators and defensive traditionalist innovators.

More specifically, the student-focused innovators think that it is up to them to stimulate students and transform them into thinkers. Students should assume responsibility for their learning and teachers should encourage students to take responsibility in all areas of their lives. Professors should assist in creating an environment and an educational setting that supports and promotes learning. They hope that their students have a broader notion of their learning than simply taking notes in preparation for the final exam.

For their part, traditionalist innovators rank teaching as the most important aspect of their work. They provide the knowledge and give students the appropriate reading lists and tools. For them, communication skills are a key quality in a professor and they do their utmost to ensure that their students pass their exams. In the case of traditionalist innovators, and unlike the previous innovator category, the student does not share the responsibility for learning; this remains solely at the teacher level.

Staff-focused innovators indicate that enthusiasm, imagination, and the ability to inspire and guide students in autonomous study are essential qualities. Their role focuses on creating an environment in which the student is encouraged to attain maturity. In contrast to the two previous categories that believe that the student or teaching lie at the heart of learning respectively, staff-focused innovators concentrate on establishing an environment that is conducive to learning to enable the student to become independent within it.

The staff-under-pressure innovators state that the best way for students to learn is through experience, by discovering for themselves and sharing their knowledge. They believe that creating an environment and an educational setting that supports learning and encourages students to take responsibility for themselves in all aspects of their lives is the key. To this end they are particularly fond of the problem-based approach. Communication skills are an indispensable quality for a professor. Creating an environment conducive to learning is crucial for staff-under-pressure innovators; however this plays a different role than for staff-focused 
innovators. Here, the environment and the educational setting must allow students to test what they discover and share it with their peers. In other words, they must be able to experience their learning.

As regards senior innovators, the latter assert that diversity is the key to good teaching. In effect, students learn in different ways; they do not believe that a single and unique good teaching method exists. They also believe that students are responsible for their own learning. Being more traditional, the senior innovators recall that learning processes differ from one student to another and, like student-focused innovators, they consider them responsible for their own learning.

The last two categories of pedagogical innovators, the professionals and the defensive traditionalists, seem the most dissimilar to the other categories. For their part, the professional innovators state that in order to play an academic role, one must demonstrate a professional contribution to the academic development of the discipline, the department, the faculty and the institution. They would like to be promoted within the university establishment. Being organised is an important quality and creating an environment and an educational setting that supports learning is part of their plan. They believe that their responsibility lies in being a constructive member of a team in any situation. Thus, professional innovators place the accent on the organisational structuring of their teaching practice within the institution.

Finally, the defensive traditionalist innovators like to benefit from the experience of others as much as conveying their own knowledge. They perceive their role of counsellor as being more important than that of teacher. This category of innovators views teaching and learning as a mutual exchange of knowledge, transforming the role of the teacher.

It also arises from Falchikov's (1993) research studies that pedagogical innovators primarily identify with the "student-focused" and "senior" professor categories, which both share "a broad view of education" (p. 488). In the author's opinion, a broad view of education entails a shift away from traditional lectures towards active student-centred methods, self-training, etc. This change requires a commitment to innovation, as well as the ability and possibility to introduce changes.

\section{Are there Differences Based on the Pedagogical Innovators' Disciplinary Culture?}

I have taken the notion of disciplinary culture as an analytical category. This means taking account of the fact that people operate within a disciplinary culture and that professors are influenced by this phenomenon. As Gaff and Wilson (1971) highlight, significant cultural differences become apparent between researchers from different faculties in relation to lifestyles, educational values and to the areas taught. These are the faculty cultures that Kolb (1981) and Becher (1989) call disciplinary cultures. Their scientific disciplines form sub-environments in which pedagogical foci, and teachers' and students' expectations and perceptions differ (Smart \& Etherington, 1995). Professors adopt a teaching approach commensurate with what they want their students to learn (Smart \& Etherington, 1995) and above all consider themselves specialists in their disciplines (Becher, 1989). It follows that the concepts of teaching held by professors are linked to their object of study (Martin et al., 2000).

Becher's (1989) categorisation seems the most relevant for the purposes and suits the division of faculties at the Université de Montréal. It consists of an integrated two-dimensional comparison process in order to highlight the differences in the degree to which a paradigm exists in a discipline. The first dimension differentiates the disciplines according to whether they are Hard, logically structured sciences that use theoretical models and frameworks and have a recognised methodology (Physics), or Soft, humanities that do not entail any restriction to the phenomena field with more idiosyncratic content and method, and justifiable complexity (literature). He also brings in the dimension of the degree of concern with application, which he defines as Pure science for the sciences that are fundamentally self-regulating (Physics), versus Applied sciences for the sciences that are open to the complexity of the environment and eclecticism (Engineering, Education). Thus, Becher's (1989) categorisation leads to four types of discipline (Pure sciences-Humanities-Applied social sciences-Applied technologies).

\section{Methodology}

The ability to describe, in detail, several important aspects of social life arising from culture and experience in order to allow the researcher to understand the internal point of view (Pires, 1997), is characteristic of the qualitative approach. Thirty-two semi-structured individual interviews with assistant, associate or full professors, all recipients of an excellence in teaching award, were conducted at the Universite de Montréal, a French-speaking institution in Quebec that is strongly committed to research. According to Becher's (1989) classification, twelve (12) professors came from Hard-Applied sciences, six (6) from Soft-Applied sciences, six 
(6) from Hard-Pure sciences and six (6) from Soft-Pure sciences. The dimensions explored during the interviews were adapted from Hannan and Silver's (2000) ten points:

1) The clarification of the interview (who I am, going through the ethics protocol and their innovations, what and when);

2) The previous history relevant to innovation (when he/she became innovator, how did it happen, in what context, alone or in collaboration);

3) Why innovate? (intention, purposes, pressures, inducements or opportunities, theory);

4) The innovation proceed (its extend, support, departmental, institutional or external, the implementation process, the responses of colleagues, students and the institution, its evaluation);

5) The life history of the innovation (Continuation, adaptation, extension/adoption);

6) The interest in the innovation (Publications, other outcomes);

7) The reflection on the process (adequacy of the support, opposition and obstacles, roles of committees and colleagues, did it survive, died, become embedded, change);

8) The personal outcomes as innovator (Is there any? Positive and negative outcomes);

9) Lessons (implications for innovation/innovators, implication for institutional organization/policy, implication for funding bodies, quality assurance); and Thanks.

Based on the professors' discourses, I constructed theories empirically, and applied the grounded theory analysis method. The reality observed and the emerging analysis allow for constant comparison in order to construct and simultaneously validate the theory (Glaser \& Strauss, 1967). Thus, the theory ensures that the result is, as it should be, "firmly grounded in empirical data" (Paillé, 1994, p. 150). I improved this iterative process of progressively theorising the phenomenon observed by following the six fundamental steps (coding, categorisation, connection, integration, modelling and theorisation) (ibid). Furthermore, accuracy and validity are ensured by a coding verification carried out by inverse coding followed by reverse coding executed by a peer. As calculated by the qualitative data-analysis program, QDA Miner, the $70 \%$ required to guarantee coding validity was achieved or exceeded for $25 \%$ of the material.

\section{Characteristics of the Innovators Interviewed in a University Strongly Committed to Research}

I wanted to explore the characteristics of the innovators interviewed. Throughout the individual interviews, the respondents actively collaborated and enriched the data collection. However, the discourse of two (2) participants has not allowed highlighting specific features or characteristics in a sufficiently pronounced way. Therefore only thirty (30) professors revealed traits and characteristics specific to their personalities in the context of pedagogical innovation within a university strongly committed to research.

Extracting the data collected during the individual interviews allowed me to centre the analysis on ten (10) sub-themes linked to the characteristics of the innovators interviewed. These are substantive categories (Glaser $\&$ Strauss, 1967) that pick up on the participants' discourses without modification.

I will now proceed to a presentation and analysis of the data, taking care to identify discursive suggestions as either extracted from interview segments, references to the literature or elements of my own interpretation. I carried out the ordered reconstruction of the professors' discourses in keeping with the research question.

Preliminarily, I recall that I considered and recognised as a reference framework Falchikov's (1993) seven categories of pedagogical innovators: student-focused innovators, traditionalist innovators, staff-focused innovators, staff-under-pressure innovators, senior innovators, professional innovators and defensive traditionalist innovators. This typology served as a back-up to the construction of a new classification, similar or close to it, based on the interpretation of the interviewed professors' discourses. In order to guide the reader I have listed the sub-themes by frequency and by case in the Table 1 . 
Table 1. List of innovator characteristics by frequency and case

\begin{tabular}{|c|c|c|c|}
\hline Sub-themes & Definition & Frequency $^{1}$ & Cases $^{2}$ \\
\hline $\begin{array}{l}\text { Collective } \\
\text { Collaborative }\end{array}$ & Pedagogical innovation is a story of teamwork and collaboration. & 3 & 3 \\
\hline Curious & It is the curiosity that drives the professor to innovate. & 1 & 1 \\
\hline Innate & $\begin{array}{l}\text { Professor believes he/she has been innovative since his birth, in an } \\
\text { innate way. }\end{array}$ & 19 & 8 \\
\hline Committed & Professor is actively involved in his/her willingness to innovate. & 6 & 4 \\
\hline Holistic & Professor conceives pedagogical innovation with a global vision. & 2 & 2 \\
\hline Passionate & $\begin{array}{l}\text { Professor is passionate about his/her teaching profession and } \\
\text { pedagogical innovations. }\end{array}$ & 32 & 18 \\
\hline Promoter & $\begin{array}{l}\text { Professor is defined as an initiator, a promoter, an instigator of } \\
\text { pedagogical innovation. }\end{array}$ & 32 & 17 \\
\hline Agitator & $\begin{array}{l}\text { Professor believes that he disturbs by his/her innovative teaching } \\
\text { practices. }\end{array}$ & 3 & 1 \\
\hline Humble & Professor does not recognize himself/herself as an innovator. & 24 & 12 \\
\hline Follower & Professor likes to get involved in innovations initiated by others. & 3 & 2 \\
\hline
\end{tabular}

Notes. 1-The frequency is the number of segments coded in relation to the sub-theme. 2-One case is one interviewed professor participating in this research. Here, this column represents the number of cases (professors) who have one or more segments coded to them by sub-theme.

I am more specifically interested in the professors' own philosophy as regards pedagogical innovation when establishing the different characteristics and this is always taken from the interviewed professors' discourses. The results emerging from the data collection have allowed me to categorise ten (10) characteristics of the pedagogical innovator as follows: Collective/Collaborative, Innate, Committed, Holistic, Passionate, Promoter, Agitator, Humble, Follower and Curious innovators. In order to provide the reader with a visual summary, I have illustrated the pedagogical innovator characteristics by case in the Figure 1 below.

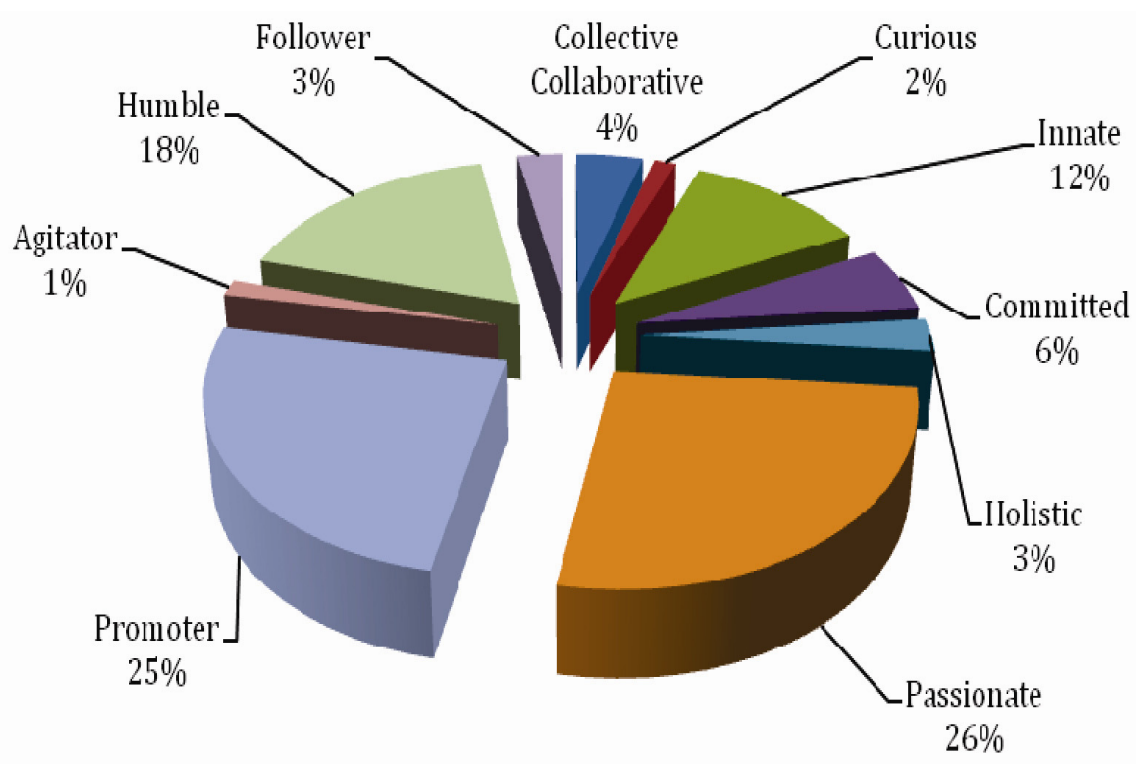

Figure 1. Illustration of innovator characteristics by case 
Collective or Collaborative innovators think that pedagogical innovation is about teamwork and collaboration. According to the experience of three of the professors interviewed, pedagogical innovation is only successful and only has an impact if it is carried out with the collaboration of other people. They also add that being part of a team of several people means that obstacles can be overcome more easily through mutual assistance.

Innate innovators believe that pedagogical innovation comes to them naturally. The discourses of eight respondents explain that innovating is something innate that they experienced very early on in their career, and also in their childhood.

Committed innovators are professors who are deeply involved with their desire to innovate. Four of the participants express great intent and involvement in each of their pedagogical innovations.

Holistic innovators perceive pedagogical innovation from a global standpoint. Two of the participants explain the importance of seeing pedagogical innovation from this perspective. In effect, this has, according to them, an impact on the development and perpetuation of the pedagogical innovation.

Passionate innovators are professors who are enthusiastic about their pedagogical innovations in particular and their teaching in general. Eighteen respondents clearly demonstrate their pride vis-à-vis their pedagogical innovation and enjoy sharing their passion with others. They claim to be very involved in the pedagogical innovation conceptually, more than in its practical integration.

Promoter innovators are instigators of pedagogical innovation and promote its development. Seventeen participants explain that it is important to innovate and seek to bring about situations conducive to pedagogical innovation, both for their own teaching and that of their peers.

The Agitator innovator believes that his innovative teaching practices cause disruption. One of the participants said that he felt awkward due the comparison that could be made between his teaching and that of his peers. He regretted often being thought of in his department as a person who disturbed the status quo of the institution.

Humble innovators do not recognise themselves as innovators. Twelve professors state that they innovate in their teaching without actually taking up the mantle of the name "innovator", which is, according to them, often equated with something harmful for the environment in which they practice.

Follower innovators get involved in the innovations initiated by others. Two respondents explain that they are not necessarily the source of the initiative or are not the one who conceived of the idea to innovate, but they are happy to join their peers' pedagogical innovation projects.

The Curious innovator explains that it is his own curiosity that drives him to innovate. One of the participants expressed a need to experiment and to test new pedagogical practices to satisfy his natural curiosity.

\section{Characteristics Rather than a Categorisation}

Unlike Falchikov's (1993) categorisation, which places each innovator into a category, the data extracted from the interviewed professors' discourses shows that often professors define themselves in more than one category. Thus, a pedagogical innovator's personality varies greatly according to the complexity of their inherent characteristics. The Table 2 allows the reader to visualise the distinctions between the respondents, whom I have given pseudonyms.

Passionate, Promoter and Humble are the characteristics with the highest number of participants. One professor (Eléonore) expressed five characteristics, Passionate, Humble, Promoter, Innate and Committed while others only evoked a single one (Evelyne, Nicolas, Sylvain, \& Gérard). Eighteen participants (Alex, Anne, Carole, Catherine, Christiane, Damien, Eva, Gabrielle, Isabelle, Kevin, Nina, Roseline, Manuel, Marc, Sophie, Simone, Tom, \& Xavier) mentioned two characteristics. Five professors (Claudia, Geneviève, Inès, Olivier, \& Ophélie) put forward three characteristics. Finally, two (Claire \& Jean) described four of them. 
Table 2. Pedagogical innovator characteristics by case

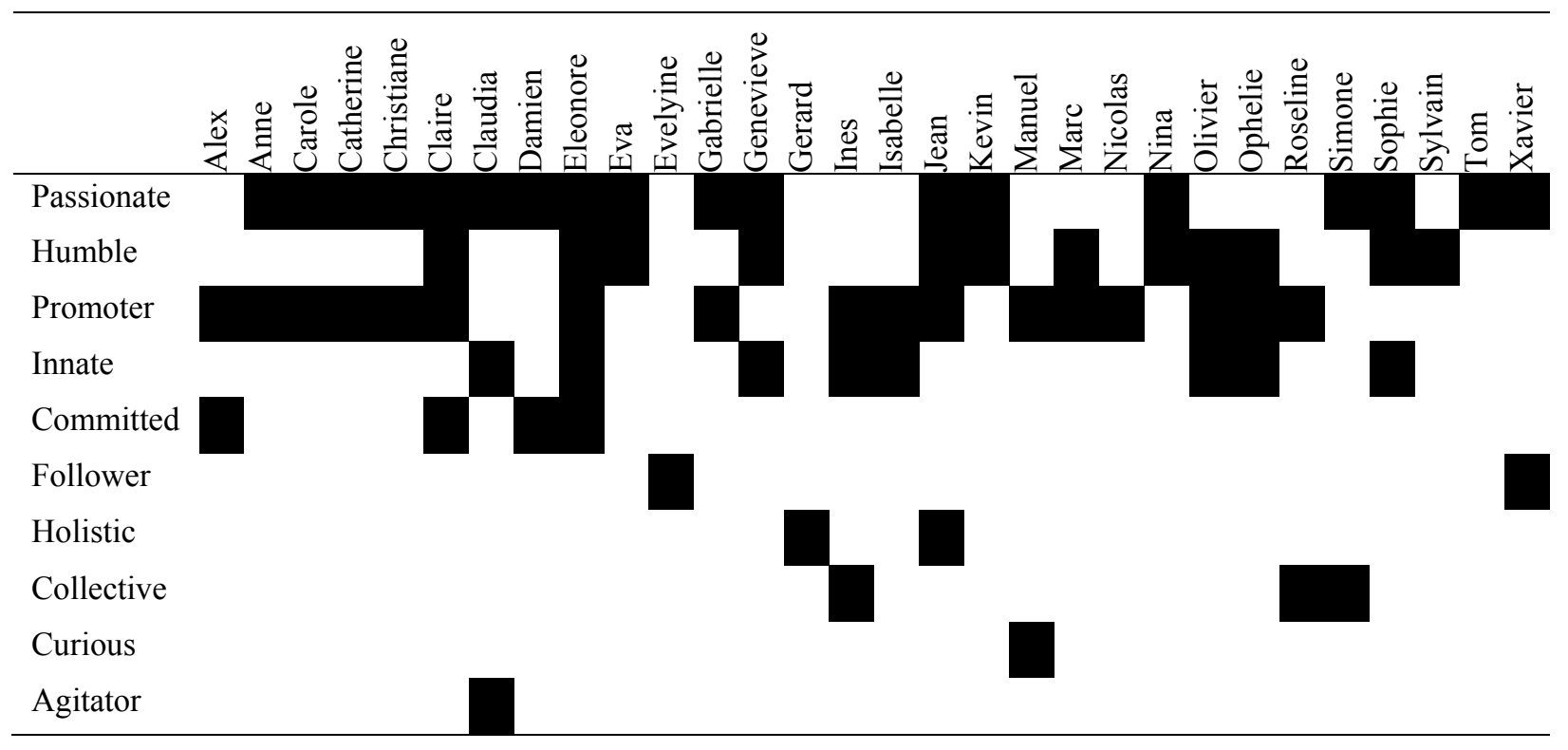

\section{Innovators' Characteristics from the Disciplinary Culture Perspective}

I previously established the following classification of the characteristics of the professors' own philosophy vis-à-vis pedagogical innovation: 1) Collective/Collaborative, 2) Innate, 3) Committed, 4) Holistic, 5) Passionate, 6) Promoter, 7) Agitator, 8) Humble, 9) Follower and 10) Curious. I have also mentioned that one professor, by virtue of their personality, can define themselves in more than one group and that the personality of a pedagogical innovator varies greatly according to the complexity of their inherent characteristics.

I have retained the notion of disciplinary culture (Becher, 1989) as an analytical category while following the faculty division existing within the Université de Montréal and more specifically the categorisation into the four discipline types defined by Becher (1989). To recap, these are Hard-Pure sciences (e.g., Biology), Soft-Pure sciences (e.g., Psychology), Hard-Applied sciences (e.g., Medicine) and Soft-Applied sciences (e.g., Education). I shall now present the analysis from this perspective. The Table 3 below illustrates the presence of the different characteristics of the innovators interviewed from the disciplinary culture perspective.

Table 3. Presence of innovator characteristics by disciplinary culture

\begin{tabular}{lllll}
\hline Characteristics of the innovators interviewed & $\begin{array}{l}\text { Sciences } \\
\text { Soft-Applied }\end{array}$ & Hard-Applied & Soft-Pure & Hard-Pure \\
\hline 1) Collective/Collaborative & 3 & 3 & & 1 \\
2) Innate & 1 & 4 & 1 & \\
3) Committed & 1 & & 1 & \\
4) Holistic & 3 & 10 & 4 & 1 \\
5) Passionate & 5 & 7 & 2 & 3 \\
6) Promoter & 1 & & 2 & 4 \\
7) Agitator & 2 & 4 & & \\
8) Humble & & 2 & & \\
9) Follower & & 1 & \\
10) Curious & &
\end{tabular}

Note. The numbers represent the cases (professors). 
I observe that the discipline categories have, according to the sample of professors, common characteristics. These are Passionate, Promoter and Humble innovators. I note that the Hard-Pure science participants do not demonstrate any unique characteristic. Nevertheless, the characteristics of professors' own philosophy vis-à-vis pedagogical innovation for the Hard-Pure sciences are the three common characteristics, and Innate.

The Soft-Pure sciences include innovators whose characteristics cover the three common ones, plus Committed and Holistic. On the Hard-Applied sciences side, Innate and Committed supplement the three common characteristics, and I find the only instances of Collective/Collaborative, Curious and Follower. For their part, the Soft-Applied sciences cover, in addition to the three common characteristics, Innate, Holistic and Committed, and have the only instances of Agitator.

At last but not the least, I observe that the Hard-Applied and Soft-Applied sciences have greater characteristic diversity than the Hard-Pure and Soft-Pure sciences.

\section{Conclusion}

In conclusion, I uphold the ten characteristics of pedagogical innovators defining themselves as innovators: Collective/Collaborative, Innate, Committed, Holistic, Passionate, Promoter, Agitator, Humble, Follower and Curious. Also, I recall that, unlike Falchikov's (1993) categorisation, my taxonomy of innovator characteristics classifies them into one or several categories.

Finally, on the one hand I highlight the fact that the applied sciences distinguish themselves from the pure sciences with unique characteristics, and on the other hand that the pure science participants display less characteristic diversity than the applied sciences. Thus, I can assert the hypothesis that the Pure versus Applied sciences axis may have an effect on innovator characteristic diversity.

I can conclude this article by confirming that several characteristic differences appear to exist among pedagogical innovators according to disciplinary culture and I note, in particular, the impact of the pure science-applied science axis on pedagogical innovator characteristic diversity.

\section{References}

Béchard, J. P. (2000). Apprendre à enseigner au supérieur: L'exemple des innovateurs pédagogiques. Cahier de recherche OIPG n 2000-001.

Becher, T. (1989). Academic tribes and territories-Intellectual enquiry and the culture of disciplines. Buckingham and Bristol: The Society for Research into Higher Education \& Open University Press.

Donnay, J., \& Romainville, M. (1996). Enseigner à l'Université: Un métier qui s'apprend? Bruxelles: De Boeck Université.

Falchikov, N. (1993). Attitudes and Values of Lecturing Staff: Tradition, Innovation and Change. Higher Education, 25, 487-510. http://dx.doi.org/10.1007/BF01383849

Fox, D. (1983). Personal theories of teaching. Studies in Higher Education, 8(2), 151-163. http://dx.doi.org/10.1080/03075078312331379014

Gaff, J. G., \& Wilson, R. C. (1971). Faculty culture and interdisciplinary studies. Journal of Higher Education, 42(3), 186-201. http://dx.doi.org/10.2307/1980354

Glaser, B. G., \& Strauss, A. L. (1967). The Discovery of Grounded Theory. Strategy for Qualitative Research, 67, 61-71.

Hannan, A., English, S., \& Silver, H. (1999). Why Innovate? Some Preliminary Findings from a Research Project on Innovations in Teaching and Learning in Higher Education. Studies in Higher Education, 24(3), 279-289. http://dx.doi.org/10.1080/03075079912331379895

Knight, P. (2002). A Systemic Approach to Professional Development: Learning as Practice. Teaching AMD Teacher Education, 18(3), 229-241. http://dx.doi.org/10.1016/S0742-051X(01)00066-X

Kolb, D. A. (1981). Learning styles and disciplinary differences. In A. Chickering (Ed.), The Modern American College. San Francisco: Jossey Bass.

Loiola, F., \& Tardif, M. (2001). Formation pédagogique des professeurs d'université et conceptions de l'enseignement. Revue des sciences de l'éducation, 27(2), 305-326. http://dx.doi.org/10.7202/009935ar

Martin, E., Prosser, M., Trigwell, K., Ramsden, P., \& Benjamin, J. (2000). What university teachers teach and how they teach it. Instructional Science, 18, 387-412. http://dx.doi.org/10.1023/A:1026559912774 
Paillé, P. (1994). L'analyse par théorisation ancrée. Cahier de recherche sociologique, 23, 147-181. http://dx.doi.org/10.7202/1002253ar

Piot, T. (2008). La construction des compétences pour enseigner. McGill Journal of Education/Revue des sciences de l'éducation de McGill, 43(2), 95-110. http://dx.doi.org/10.7202/019577ar

Pires, A. (1997). De quelques enjeux épistémologiques d'une méthodologie générale pour les sciences sociales. In J. Poupart, J. P. Deslauriers, L. H. Groulx, A. Laperrière, R. Mayer, \& A. Pires (Eds.), La recherche qualitative. Enjeux épistémologiques et méthodologiques (pp. 51-52). Montreal: Gaëtan Morin.

Smart, J. C., \& Etherington, C. A. (1995). Disciplinary and Intellectual Differences in Undergraduate Education Goals. In N. Hativa, \& M. Marincovich (Eds.), Disciplinary Differences in Teaching and Learning: Implications for Practice (No. 64, Winter). San Francisco: Jossey-Bass.

Weimer, M., \& Lenz, L. F. (1991). Instructional interventions: A review of the literature on efforts to improve instruction. In J. Smart (Ed.), Handbook of theory and research (pp. 294-333). New York: Agathon.

\section{Copyrights}

Copyright for this article is retained by the author(s), with first publication rights granted to the journal.

This is an open-access article distributed under the terms and conditions of the Creative Commons Attribution license (http://creativecommons.org/licenses/by/3.0/). 